\title{
Rotational Acquisition
}

National Cancer Institute

\section{Source}

National Cancer Institute. Rotational Acquisition. NCI Thesaurus. Code C69229.

Acquisition of an image where the X-ray source rotates around the subject. 